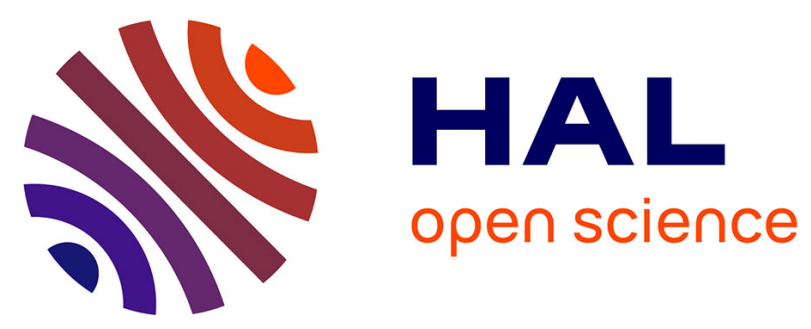

\title{
Self-mineralization and assembly of a bis-silylated Phe-Phe pseudodipeptide to a structured bioorganic-inorganic material
}

Said Jebors, Laurine Valot, Cécile Echalier, Baptiste Legrand, Remi Mikhaleff, Arie van Der Lee, Raul Arenal, Pascal Dumy, Muriel Amblard, Jean Martinez, et al.

\section{To cite this version:}

Said Jebors, Laurine Valot, Cécile Echalier, Baptiste Legrand, Remi Mikhaleff, et al.. Selfmineralization and assembly of a bis-silylated Phe-Phe pseudodipeptide to a structured bioorganicinorganic material. Materials Horizons, 2019, 6 (10), pp.2040-2046. 10.1039/c9mh00580c . hal02372976

\section{HAL Id: hal-02372976 https://hal.science/hal-02372976}

Submitted on 20 Dec 2019

HAL is a multi-disciplinary open access archive for the deposit and dissemination of scientific research documents, whether they are published or not. The documents may come from teaching and research institutions in France or abroad, or from public or private research centers.
L'archive ouverte pluridisciplinaire HAL, est destinée au dépôt et à la diffusion de documents scientifiques de niveau recherche, publiés ou non, émanant des établissements d'enseignement et de recherche français ou étrangers, des laboratoires publics ou privés. 


\title{
Self-mineralization and assembly of a bis-silylated Phe-Phe pseudodipeptide to a structured bioorganic-inorganic materialt
}

\author{
Saïd Jebors, ${ }^{a}$ Laurine Valot, ${ }^{\mathrm{a}, \mathrm{b}}$ Cécile Echalier, ${ }^{a}$ Baptiste Legrand, ${ }^{a}$ Remi Mikhaleff, ${ }^{a}$ Arie Van Der \\ Lee, ${ }^{\mathrm{c}}$ Raul Arenal, ${ }^{\mathrm{d}}$ Pascal Dumy, ${ }^{\mathrm{a}}$ Muriel Amblard, ${ }^{\mathrm{a}}$ Jean Martinez, ${ }^{\mathrm{a}}$ Ahmad Mehdi, ${ }^{* \mathrm{~b}}$ and Gilles \\ Subra*a
}

\begin{abstract}
Self-mineralization of trialkoxysilyl hybrid peptide yield in a single step a nanostructured hybrid material. A bis-silylated pseudodipeptide inspired from the Phe-Phe dipeptide was used to program the assembly by sol-gel polymerization in heterogeneous conditions, in water at $\mathrm{pH} 1.5$ without any structure-directing agent. A mechanism deciphering the hybrid material assembly was proposed thanks to $1 \mathrm{H}$ NMR spectroscopy. First, water-insoluble hybrid building blocks were hydrolysed into their soluble silanol counterparts. Then, these transitional species, thanks to hydrogen bonding and $\pi-\pi$ stacking, self-assembled in solution. Last, the proximity of silanol moieties favoured their polycondensation into growing siloxane oligomers, which spontaneously precipitated to produce an ordered hybrid material.
\end{abstract}

The control of shape and organization of matter at the nanoscale is of major interest for nanoscience. ${ }^{1,2}$ This can be achieved by a bottom-up strategy involving the self-assembly of molecules. Peptides are very attractive building blocks for this approach by the functionalities afforded by the side chains of amino acids, and their three-dimensional structures offer a large diversity of potential interactions and intermolecular arrangements.

Chemists being inspired by the natural recognition systems driving the formation of nanostructures. Thus, considerable works have been done on self-assembly of synthetic peptides in the last decades. Secondary structures such as $\alpha$-helices, polyproline (PP) helices, and $\beta$-strands, have been used to design fibrous peptide materials and hydrogels. They are obtained by self-assembly through hydrogen bonding in case of $\beta$-sheets ${ }^{3}$ and principally by side chain or $\mathrm{N}$ - and $\mathrm{C}$ - terminus interactions in the case of $\alpha$ helical ${ }^{4}$ and PPII systems. ${ }^{56}$ Peptide amphiphiles (PA) have also been used to obtain nanofibers. Their assembly is mostly driven by the lipid tail, a region devoted to $\beta$-sheet formation through repetitive bonding and charged end-regions. ${ }^{78}$ Interestingly, PA can be functionalized by bio relevant sequences such as anionic nucleation templates for biomineralization with hydroxyapatite, mimicking in some way the process of bone tissue formation. ${ }^{9}$ Another example of biomineralization is the dynamic self-assembly of peptide silica fibres (1) ined from the cyclic $\beta$-sheet forming peptide lanreotide.

\footnotetext{
a. IBMM, Univ Montpellier, CNRS, ENSCM, Montpellier, France

b.ICGM, Univ Montpellier, CNRS, ENSCM, Montpellier, France

c. IEM, Univ Montpellier, CNRS, ENSCM, Montpellier, France

d. Laboratorio de Microscopias Avanzadas (LMA), Instituto de Nanociencia de

Aragon (INA), Universidad de Zaragoza, C/ Mariano Esquilor s/n 50018 Zaragoza, Spain

Corresponding Authors

*gilles.subra@umontpellier.fr

*ahmad.mehdi@umontpellier.fr
}

Stacking and arrangement of dimers of the cationic lanreotide catalyse condensation of the anionic silicic acid through charge neutralization, enabling the growth of silica-peptide micrometric fibres. ${ }^{10}$ Aside from the fundamental understanding of how nature manufactures 'hard' and highly structured macroscopic objects (bones, shells, teethes, etc.) from soluble nanometric biomolecules, mineralization of self-assembled scaffolds can be attractive to design new bioinspired nanomaterials with increased stability and resistance.

On the other hand, the sol-gel process is the route of choice to obtain silica and hybrid organic/inorganic materials. It involves the hydrolytic condensation of alkoxysilane precursors at room temperature. Noteworthy, the use of surfactants during the sol-gel process yield highly ordered mesoporous silica's (OMS). ${ }^{11-13}$ Hybrid bioorganic materials are mostly obtained by post-functionalization of the silica and by non-covalent adsorption of biomolecules. On the opposite, we described that hybrid peptide units, bearing at least one triakoxysilyl group could be used as a building block to prepare peptide-silica hybrid materials through the sol-gel protocol. ${ }^{1415}$ At the same time, we demonstrated that highly functionalized lamellar silica could be easily obtained by hydrolysis and polycondensation of a simple organosilane, in water and without any structure-directing agent (SDA). ${ }^{16-18}$ In that context, we decided to use hybrid trialkoxysilyl peptides for elaboration of nano structured materials via the 'self-mineralization' of hybrid peptide building blocks displaying self-recognition properties. (Fig. 1)

Hybrid peptide

Structured hybrid material

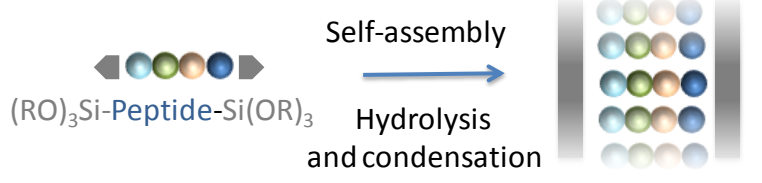

Fig. 1 Principle of self-mineralization of bis-silylated peptide.

On the contrary to existing methods for the synthesis of hybrid materials, some key features can be pointed out. First, our approach does not require addition of any inorganic charge such as tetraethoxysilane (TEOS), silicic acid or phosphate and calcium salts to mineralize the peptide assembly. Second, it does not require any SDA as such used to obtain ordered mesoporous silica (OMS).

To demonstrate the feasibility of this approach, we took inspiration from the dipeptide sequence Phe-Phe, perhaps the 
simplest self-recognition element in peptide sequences. ${ }^{19}$ Diphenylalanine is the main Alzheimer's $\beta$-amyloid recognition motif and self-assemble into ordered stiff nanotubes. ${ }^{20}$ Since its discovery, a large number of other aromatic dipeptides ${ }^{21}$ were used to obtain various assembled materials such as fibrils, nanowires, nanotubes, vesicles, depending on the conditions of formation. ${ }^{2223}$ The basis of the assembly proceeds first by non-covalent assembly of a cycle formed by several dipeptides (six dipeptides in the case of the seminal $\mathrm{H}$-Phe-Phe-OH sequence) brought together by carboxylic acid and amine interactions. Each non covalent cyclic peptide can seat on the top of another one, thanks to aromatic $\pi$-stacking, yielding a hollow tube, which in turn packs laterally with another tube to give a supramolecular object. ${ }^{24}$

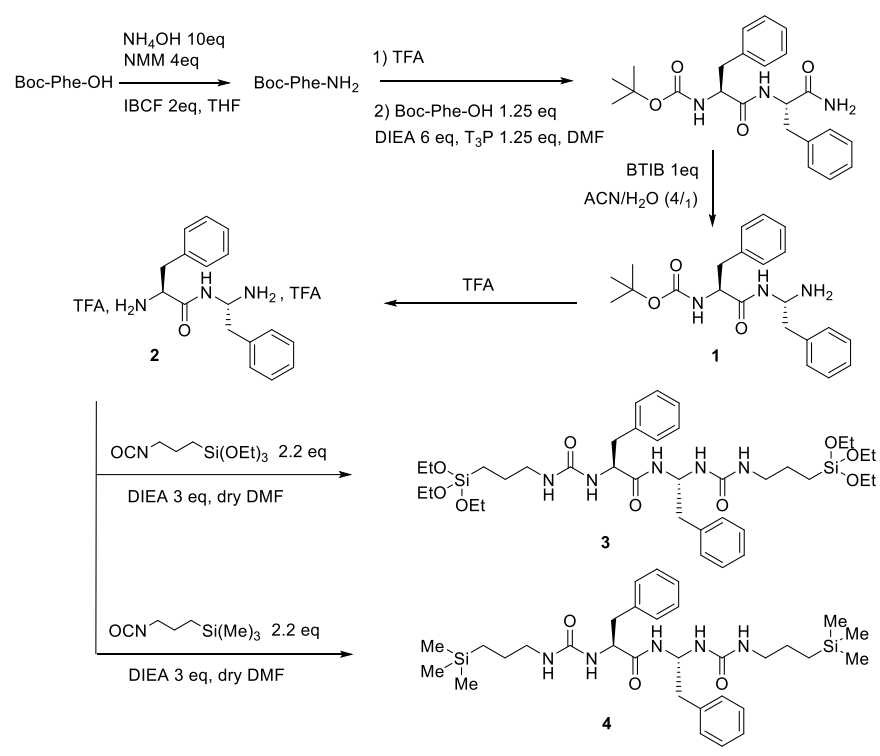

Scheme 1 Synthesis of bis-silylated pseudodiphenylalanine building blocks 3 and $\mathbf{4}$.

Based on these mechanisms, we designed the hybrid building block 3, which satisfies four requirements: (i)-it displays the two phenylalanine side chain benzyl groups in the same orientation than the original all (L) diphenylalanine; (ii)-it presents two triethoxysilyl functionalities, which should 'freeze' covalently the structure by inorganic polymerization; (iii)-it should favour a strong $\mathrm{H}$-bonding network through the urea functions replacing the carboxylateammonium interactions of the original H-Phe-Phe-OH; (iv)-the building block has to be as symmetrical as possible, presenting the silyl group in an even manner at both sides of the di aromatic template.

To address the last requirement, a gem diamino phenylalanine was synthesized to get a primary amine function substituting the $\mathrm{C}$ ter function of $\mathrm{H}$-Phe-Phe-OH. The key step of the synthesis of $\mathrm{H}$-PhegemPhe-H 2 (Scheme 1, and Fig. S1, ESI) is a Hoffmann rearrangement ${ }^{25}$ to convert the $\mathrm{C}$-ter amide to the transient corresponding isocyanate, which was hydrolysed into the primary amine with evolving $\mathrm{CO}_{2}$. The pseudopeptide 1 (Boc-Phe-gemPhe-H) was recovered by precipitation in diethyl ether in a $92 \%$ very good yield. Following Boc removal by TFA treatment (Figure S2), the gem- diamino peptide 2 presenting two primary amine functions was reacted with 2.2 equivalents of 3-isocyanatopropyltriethoxysilane (ICPTES) to yield the hybrid building block $\mathbf{3}$. The silylation reaction took place in dry DMF under inert argon atmosphere to avoid the premature hydrolysis and the subsequent polycondensation of alkoxysilane groups. At the end of the reaction, the hybrid pseudopeptide $\mathbf{3}$ was precipitated in diethyl ether and dried overnight under vacuum. The reaction was quantitative and compound 3 was characterized by ESI+ LC/MS and ${ }^{1} \mathrm{H},{ }^{13} \mathrm{C},{ }^{29} \mathrm{Si} N M R$, (Figures S3-S6) before being stored at $4^{\circ} \mathrm{C}$ under argon atmosphere. Noteworthy, compound $\mathbf{4}$ containing trimethylsilyl groups was also synthesized as a stable analogue to verify the self-assembly of the building block (Fig. S7-S10, ESI). Indeed, it is unable to undergo solgel inorganic polymerization. Compound $\mathbf{4}$ was recrystallized from hot ethanol and the obtained single-crystal structure was analyzed. The structure shows three independent molecules with perfect alignment of phenyl groups and $\mathrm{H}$-bonding between urea and amide parts of the pseudopeptide that confirms the lamellar arrangement (Fig. 2). The three molecules of $\mathbf{4}$ in the unit cell differ in the orientation of the trimethylsilane groups with respect to the molecule backbones (Fig. S11-S13, ESI). Molecules are connected by relatively strong classical hydrogen bonds of $2.20 \AA$ (Fig. 2), forming a stacked sequence along the $b$-axis., the distance between two aromatic cycle can be evaluated to be around $5.2 \AA$ and this distance is largely lower than $6.5 \AA$, proving the presence of $\pi$ - $\pi$ stacking. ${ }^{26}$

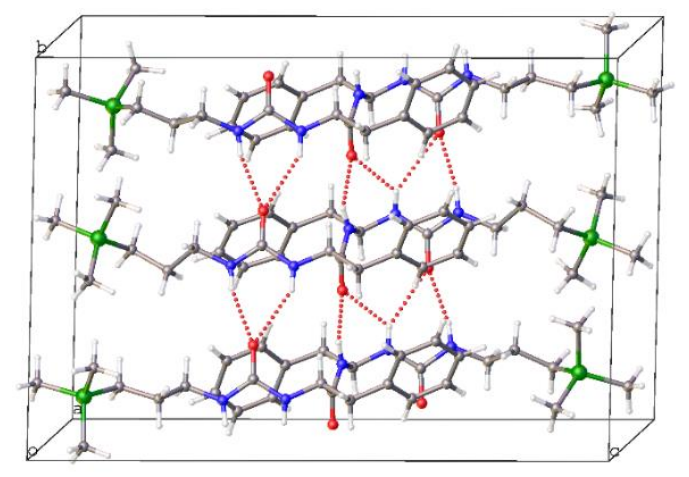

Fig. 2 Crystal structure of compound $\mathbf{4}$ in the unit cell.

Once self-assembly of the building block was evidenced, reactive precursor $\mathbf{3}$ was used for the preparation of hybrid materials by selfassembly driven sol-gel process. The sol-gel chemistry proceeds in two steps: 1) hydrolysis of the alkoxysilanes into silanols groups ( $\mathrm{SiOH}$ ), and 2) condensation of SiOH into siloxanes (Si-O-Si). In acidic aqueous solution ( $\mathrm{pH}$ 1.5), hydrolysis of the triethoxysilane is fast. On the contrary, condensation does not proceed, and silanols do not spontaneously react together to yield siloxanes bonds. Thus, when polymerization occurs at $\mathrm{pH} 1.5$, this condensation is driven by a selfassembly process, distributing the silanols in close vicinity. ${ }^{[25,26]}$ Two different procedures have been assayed to obtain a hybrid material from the hybrid block 3, using homogeneous (route A) or heterogeneous (route B) conditions. In homogeneous conditions, the silylated peptide 3 was solubilized at $38.5 \mathrm{mM}$ in a mixture of water $(\mathrm{HCl}, \mathrm{pH} 1.5) / \mathrm{THF}(1 / 1, \mathrm{v} / \mathrm{v})$ solution. It is worth noting here that the organic solvent was necessary to solubilize compound $\mathbf{3}$ after 
sonication. Even after total hydrolysis of EtOSi groups, the solution remained limpid for several days, clearly indicating that the inorganic polymerization did not proceed. This observation could be explained by the lack of self-assembly due to the damaging effect of THF on the establishment of hydrogen bonding as a driving force of the mineralization process. ${ }^{29}$ Failing to observe any precipitate, the solvent was then slowly removed under an extractor hood to induce the polycondensation process. In fact, after solvent evaporation, a white solid (noted M3A) was obtained in the bottom of the beaker, and was observed by SEM (Fig. S14, ESI). The worm-like solid obtained witnessed that the condensation took place during evaporation, which forced the Si-O-Si bond formation by water evolving, without any self-assembly. This result was confirmed by $\mathrm{X}$ ray diffraction analysis (Fig. 3). In fact, the XRD pattern for M3A exhibited only one low-angle diffraction peak $(d 100)$ at $2.69^{\circ}$ corresponding to the d-spacing of $3.29 \mathrm{~nm}$ attributed to the correlation distance between the inorganic parts.

Alternatively, heterogeneous conditions were assayed. The silylated pseudopeptide 3 was poured into water $(\mathrm{HCl}, \mathrm{pH} 1.5)$ with the same ratio weight/volume of solution than in the previous experiment (theoretical concentration: $38.5 \mathrm{mM}$ ). As already stated, compound $\mathbf{3}$ was insoluble in water and thus remained as a powder on the surface. The heterogeneous mixture was left under magnetic stirring for four days. This white sedimented solid was filtered, washed with acidic water $(\mathrm{pH} \mathrm{1.5)}$ and dried under vacuum, for 40 minutes at $50^{\circ} \mathrm{C}$ to give quantitatively the corresponding hybrid material called M3B. In striking contrast with the previous solid obtained by evaporation, MEB analysis showed well organized superimposed hybrid sheets of $>10 \mu \mathrm{m}$ length (Figure 4), and TEM analysis clearly showed lamellar sheets. Noteworthy, placed in the same conditions, compound $\mathbf{4}$ did not yield any precipitate and remained intact as expected since $\mathrm{C}-\mathrm{SiMe}_{3}$ groups are very stable under these conditions. To be sure that no degradation of the pseudodipeptide occurs during the process, an NMR is done at the beginning of the reaction with the compound $\mathbf{4}$ and after 7 days, and showed its stability at this acidic pH (Fig. S15, ESI).

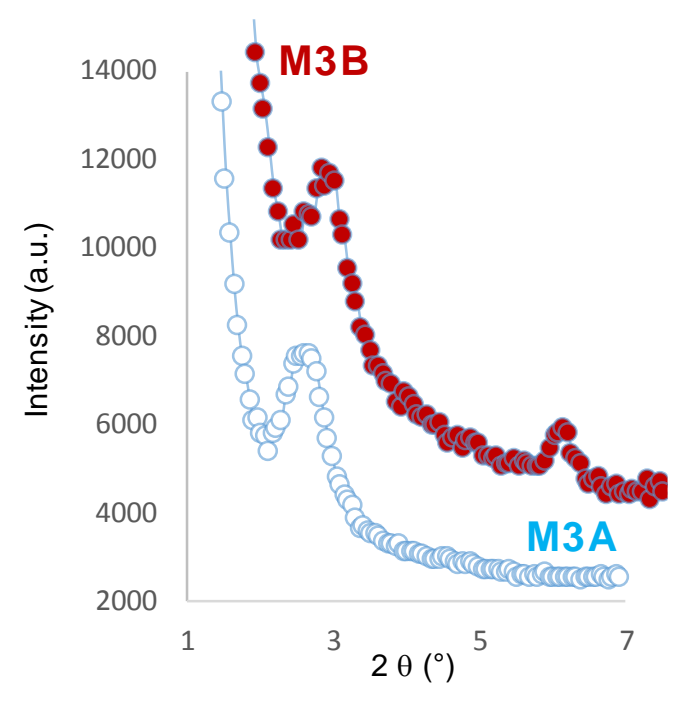

Fig. 3 XRD patterns of materials M3A and M3B.
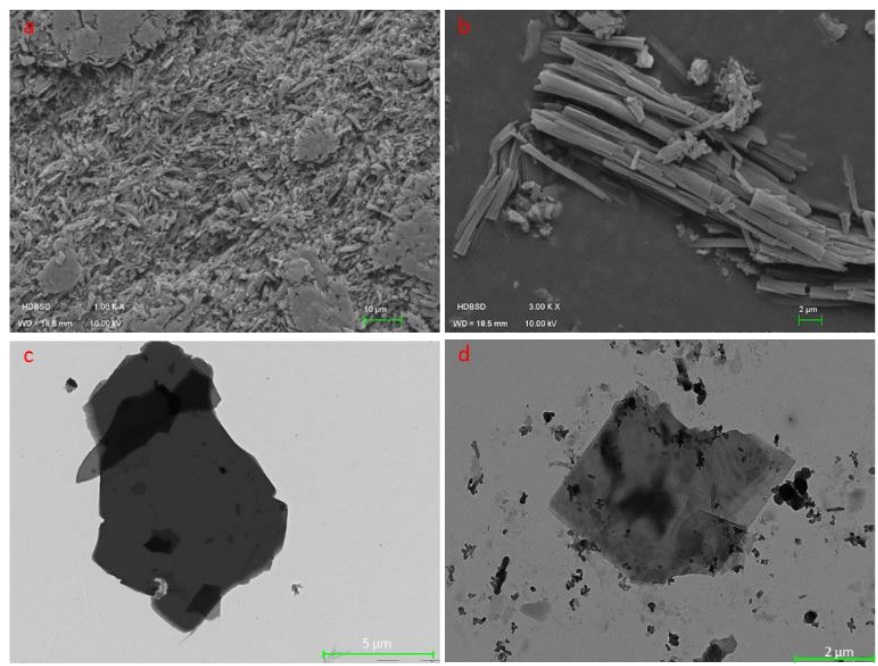

Fig. $4 \operatorname{SEM}(a$ and $b$ ) and TEM images ( $c$ and $d$ ) of nanometric hybrid superimposed sheets $\mathbf{M} \mathbf{3}$ B obtained by sol-gel polymerization of $\mathbf{3}$ in heterogeneous conditions in water at $\mathrm{pH}$ 1.5.

A supposed mechanism was proposed for the formation of such organized solid (Scheme 2). First, water-insoluble hybrid building blocks 3, were hydrolysed into their soluble silanol $\left[\mathrm{Si}(\mathrm{OH})_{3}\right]$ counterparts. Then, these transitional species, thanks to hydrogen bonding and $\pi-\pi$ stacking, tended to self-assemble in solution. Last, the proximity of silanol moieties probably favours their polycondensation into siloxanes dimers and growing oligomers, which spontaneously precipitated as ordered hybrid material. Several experiments supported this mechanism. We first studied the course of events in solution using ${ }^{1} \mathrm{H}$ NMR spectroscopy (Scheme 2 and Fig. S16, ESI). For that, the hybrid pseudopeptide $\mathbf{3}$ (with the same ratio weight/volume of solution than in the previous 
experiment meaning $38.5 \mathrm{mM}$ ) was placed in $\mathrm{D}_{2} \mathrm{O}$ and $\mathrm{pH}$ was adjusted to 1.5 using $\mathrm{DCl}$. We followed the hydrolysis and polycondensation steps for 78 hours, monitoring unambiguous probes, i.e. resonances of ethanol produced during the hydrolysis $\left(\delta \mathrm{CH}_{2}=3.6 \mathrm{ppm}\right.$ and $\left.\delta \mathrm{CH}_{3}=1.1 \mathrm{ppm}\right)$, aromatic protons of the peptide moiety (centred around $7.3 \mathrm{ppm}$ ), and methylene protons in $\alpha$ of the alkoxysilane groups $\left(\delta^{\alpha} \mathrm{CH}_{2}=0.5\right.$ and $\left.0.6 \mathrm{ppm}\right)$. At $\mathrm{t}=15 \mathrm{~min}$, we only observed very small signals corresponding to ethanol and we could not detect any trialkoxysilylated hybrid pseudopeptide $\mathbf{3}$ resonances, since it was insoluble. We observed that ethanol signals rapidly increased with time until $7 \mathrm{~h}$, then moderately until $49 \mathrm{~h}$, and very slowly for the last 19 hours of experiments. Concomitantly, the intensity of the hybrid pseudopeptide resonances increased, since the hydroxysilylated derivatives were soluble even at high concentrations, reaching a plateau after $49 \mathrm{~h}$ (Scheme 2). We could notice that phenylalanine aromatic signals came from various soluble pseudopeptide species, both hydrolysed (and partially hydrolysed) pseudopeptide $\mathbf{3}$ monomers, and partially condensed oligomers. Thus, hydrolysis of EtOSi groups occurred rapidly after the contact of 3 with the acidic aqueous solution, releasing ethanol molecules, while as expected, the hydroxysilylated hybrid pseudopeptide concentration quickly increased. Interestingly, the weak but regular increase of the ethanol concentration while the pseudopeptide concentration remained stable after $49 \mathrm{~h}$, should indicate that a proportion of the either peptide precipitated or was polycondensed to form large objects that could not be detected using liquid-state NMR spectroscopy. Fortunately, the hydrolysis and condensation events could be simultaneously monitored, following the intensity and the chemical shift of the adjacent methylene groups to the silicon atoms (Scheme 2). First, the ${ }^{\alpha} \mathrm{CH}_{2}$ signals at $0.5 \mathrm{ppm}$ belonging to the hydroxysilylated species quickly increased like the phenylalanine aromatic protons during the early phase of the hydrolysis until $3 \mathrm{~h}$. Then, it decreased regularly until $49 \mathrm{~h}$ and only a small residual signal remained until the end of the experiments. It is noteworthy that a ${ }^{\alpha} \mathrm{CH}_{2}$ signal at $0.6 \mathrm{ppm}$ probably arising from the partially condensed oligomeric species not large enough to precipitate. Being soluble, these partially condensed species could be detected after $3 \mathrm{~h}$, when the drop of the ${ }^{\alpha} \mathrm{CH}_{2}$ signal at $0.5 \mathrm{ppm}$ occurred. Then, the intensity of the ${ }^{\alpha} \mathrm{CH}_{2}$ resonances at 0.5 and 0.6 ppm evolved in an opposite way until being stable at $46 \mathrm{~h}$, the 0.6 ppm signal being largely predominant. Thus, we could reasonably hypothesize that the concentration of hydroxysilylated species necessary for the condensation was reached after $3 \mathrm{~h}$ and the proportion of partially condensed species increased until $46 \mathrm{~h}$. At the end of experiment after 78 hours, the main species in solution was the partially condensed hybrid peptide, while the organized hybrid peptide material precipitated.

The organized solid M3B was then studied. First, we verified the covalent nature of the assembly by placing the solid in usual organic solvents (alcohol, DMF, DMSO ...) even in TFA. As expected, the solid did not solubilized confirming the formation of siloxane bonds. In fact, the ${ }^{29} \mathrm{Si}$ CP-MAS NMR spectrum of M3B (Figure S19, ESI) displayed two peaks at -57 and $-66.0 \mathrm{ppm}$ attributed to $\mathrm{T}^{2}$ [C$\left.\mathrm{Si}(\mathrm{OH})(\mathrm{OSi})_{2}\right]$ and $\mathrm{T}^{3}\left[\mathrm{C}-\mathrm{Si}(\mathrm{OSi})_{3}\right]$ substructures. The percentage of $\mathrm{T} 1$,
T2 and T3 substructures was found to be 5.5, 46.5 and 48 respectively and the condensation rate was estimated to be around $81 \%$. In addition, the absence of resonance near $-100 \mathrm{ppm}$ corresponding to $\mathrm{Q}$ substructures $\left(\mathrm{Si}(\mathrm{OSi})_{4}\right)$ denoted also that there was no cleavage of $\mathrm{Si}-\mathrm{C}$ bonds during the sol-gel process. This stability was confirmed by $\mathrm{C} / \mathrm{N}$ ratio, which is in good agreement with theoretical one, obtained from elemental analysis (Table S1, ESI). Infrared spectroscopy was performed on M3B and the spectrum shows clearly the presence of an intense band centered at $1150 \mathrm{~cm}$ 1 assigned to Si-O-Si bonds (Figure S2O and table S2). In addition to all bands characteristic to the peptide units, a band at $3300 \mathrm{~cm}^{-1}$ attributed to uncondensed $\mathrm{SiOH}$ groups. In addition, two prominent features, the amide I ( $1650 \mathrm{~cm}-1)$ and amide II ( 1560 cm-1) bands, where the former arise primarily from the $\mathrm{C}=\mathrm{O}$ stretching vibration and the latter is attributed to the $\mathrm{N}-\mathrm{H}$ bending. The difference $(\Delta \mathrm{v})$ between the two vibration modes (amide I and amide II) was found to be very close to those observed in the compound $\mathbf{3}$ and $\mathbf{4}$ at solid state. Indeed, the $\Delta v$ values are often used to give a good indication of the strength of the $\mathrm{H}$-bonds between ureido groups, the lower the $\Delta v$ values; the stronger the $H$-bonding interactions are (Table S3, ESI). By contrast to M3A, the XRD pattern for M3B (Figure 3) exhibited two low-angle diffraction peaks ( $d 100$ and $d 200$ ) at 2.84 and $5.70^{\circ}$ corresponding to the d-spacings of $3.11 \mathrm{~nm}$ and $1.55 \mathrm{~nm}$ respectively. The peak observed at the higher angles is attributed as the second-order harmonic of the first peak and its presence

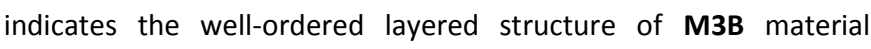
obtained in water. Such differences of the solid structures obtained in different conditions was already observed and discussed in the literature, ${ }^{28-31}$ and endorse the importance of the solvent in the control of the assembly of hybrid material during the sol-gel process. There is no one-to-one correspondence between the observed $d$ spacings in the diffractogram of M3B and the length of the monomer which can be approximately deduced from the single-crystal structure of compound 4, The repeat distance in the hydrolysed (polymeric) structure of $\mathbf{M} 3 \mathbf{B}$ deduced from this monomer structure is about $2.10 \mathrm{~nm}$, which obviously does not correspond to the observed d-spacing of $3.11 \mathrm{~nm}$. This means most probably that the 
principal repeat vector in $\mathbf{M} 3 \mathbf{B}$ is not aligned with the monomer long axis and/or that a centred unit cell in M3B is formed.

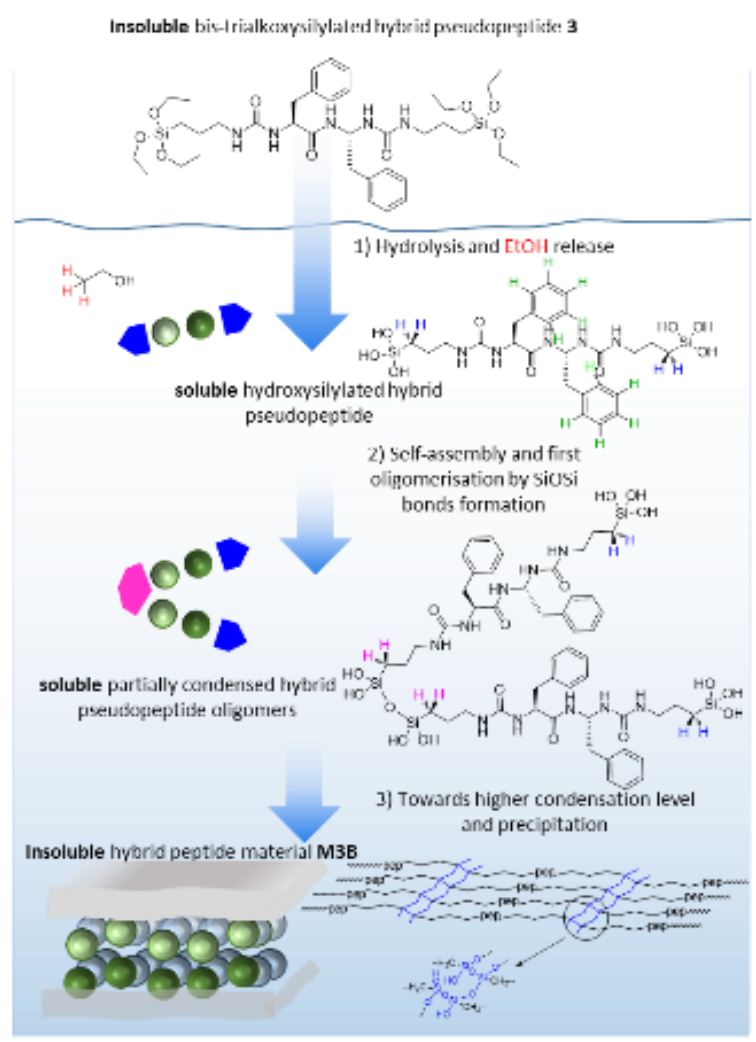

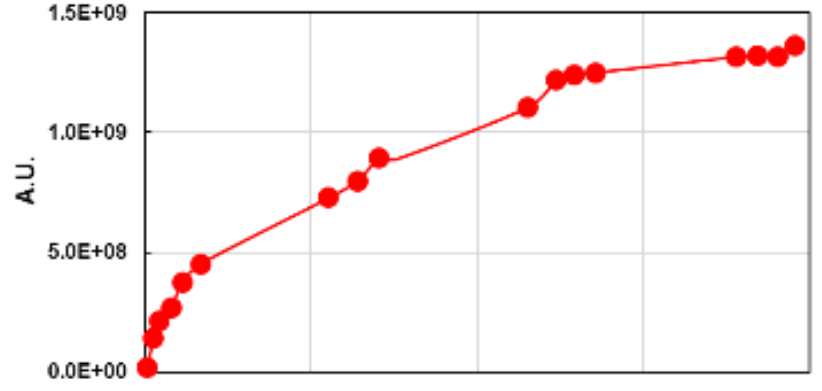

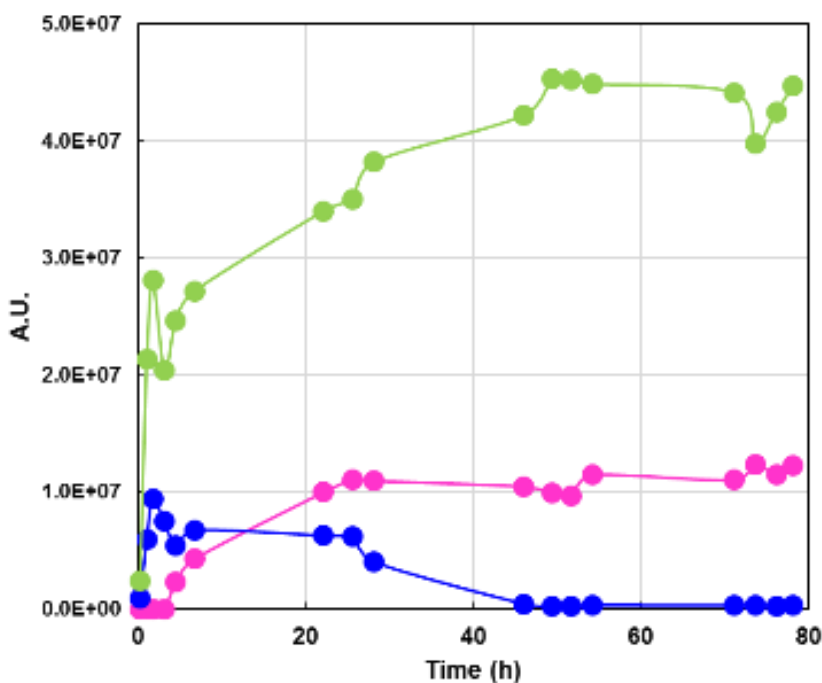

Scheme 2 Putative mechanism of self-assembly and self-mineralization of hybrid block $\mathbf{3}$ in water, $\mathrm{pH} 1.5$ and integration of ${ }^{1} \mathrm{H}$ NMR signals of some relevant proton signals with their time evolution.

To assess that the structure of the material is made by the selfassembly of the peptide, an unsymetric silylated PhegemPhe pseudosipeptide $\mathbf{5}$ was prepared with a non-reactive trimethylsilyl moiety and a reactive triethoxysilyl one (Scheme S1 and Fig. S23-S28, ESI). A new material M5 is prepared with the same process than M3B. TEM images showed a semi organized material (Fig. 5A), and XRD analysis confirmed this (Fig. S30, ESI).

Another possibility was to prepare a building block 6 without pistacking but sterically overloaded (and unpolar) to compare with compound 3 and their relative materials (M6 and M3B). This compound is made with a bis-silylated pseudodileucine (Scheme S2 and Fig. S31-S37, ESI) and the material is prepared with the same process than M3B. It is interesting to notice that because of lack of self-assembly, the yield is relatively low compared to other materials. When analysed by TEM (Fig. 5B), only amorphous objects are observed, proving that the peptidic sequence did not lead to organized structure. XRD analysis also confirmed this (Fig. S39, ESI). 


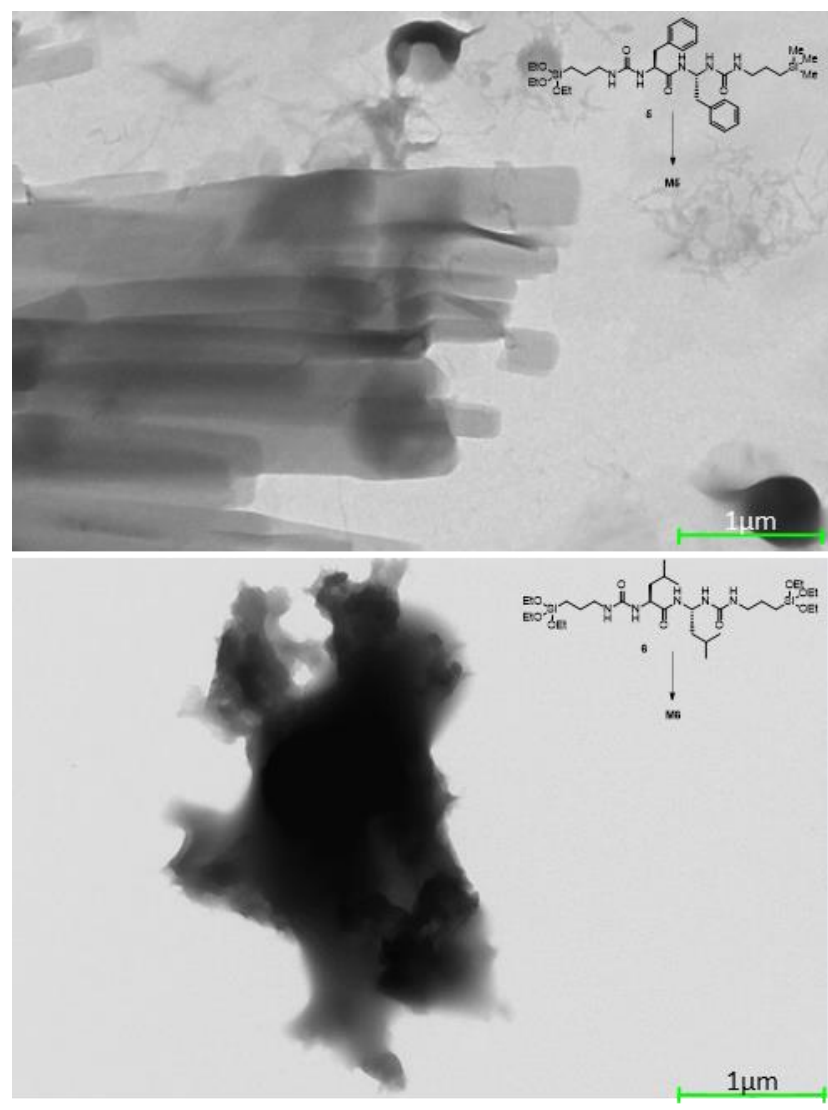

Fig. 5 SEM image of nanometric mateirals M5 (a, $2 \mu \mathrm{m}$ scale bar) and $\mathbf{M 6}(\mathrm{b}, 1 \mu \mathrm{m})$ obtained by sol-gel polymerization of 5 or $\mathbf{6}$ in heterogeneous conditions in water at $\mathrm{pH}$ 1.5.

\section{Conclusions}

Using a tailored building block, which displays self-recognition properties, it is possible to edify supramolecular assemblies, formed though the establishment of a network of non-covalent weak interactions. However, by nature, most of these architectures only transiently exist, and must undergo chemical cross-linking to acquire better stability. Alternatively, these building blocks may be used as templates for the deposition of an inorganic layer and the recovery of the hybrid material. Herein we have demonstrated it was possible to obtain in a single step bioorganic-inorganic architectures, by adding alkoxysilanes at suitable position on a building block programmed for the irreversibility of the self-assembly. Combining the wide range of peptide recognition motives and the simplicity of sol-gel 'soft' chemistry, we expect to provide a simple and predictable tool to organize matter at the nanometric scale.

\section{Experimental section}

Details on the experimental procedures are provided in the ESI. ${ }^{\dagger}$

\section{Conflicts of interest}

\section{Acknowledgements}

This work was funded by the ANR (Agence Nationale de la Recherche), the French National Research Agency (ANR-16CE18-0003).

Peptide syntheses and purifications were performed using SynBio3 platform facilities supported by GIS IBISA and ITMO Cancer.

\section{References}

1 K. Thorkelsson, P. Bai and T. Xu, Nano Today, 2015, 10, 48-66.

2 E. Busseron, Y. Ruff, E. Moulin and N. Giuseppone, Nanoscale, 2013, 5, 7098.

3 M. C. Branco and J. P. Schneider, Acta Biomater., 2009, 5, 817831.

4 D. Papapostolou, A. M. Smith, E. D. T. Atkins, S. J. Oliver, M. G. Ryadnov, L. C. Serpell and D. N. Woolfson, Proc. Natl. Acad. Sci., 2007, 104, 10853-10858.

5 F. W. Kotch and R. T. Raines, Proc. Natl. Acad. Sci. U. S. A., 2006, 103, 3028-3033.

6 L. E. R. O'Leary, J. A. Fallas, E. L. Bakota, M. K. Kang and J. D. Hartgerink, Nat. Chem., 2011, 3, 821-828.

7 G. A. Silva, C. Czeisler, K. L. Niece, E. Beniash, D. A. Harrington, J. A. Kessler and S. I. Stupp, Science, 2004, 303, 1352-1355.

8 K. L. Niece, J. D. Hartgerink, J. J. J. M. Donners and S. I. Stupp, J. Am. Chem. Soc., 2003, 125, 7146-7147.

9 J. D. Hartgerink, E. Beniash and S. I. Stupp, Science, 2001, 294, 1684-1688.

10 E. Pouget, E. Dujardin, A. Cavalier, A. Moreac, C. Valéry, V. Marchi-Artzner, T. Weiss, A. Renault, M. Paternostre and F. Artzner, Nat. Mater., 2007, 6, 434-439.

11 J. S. Beck, J. C. Vartuli, W. J. Roth, M. E. Leonowicz, C. T. Kresge, K. D. Schmitt, C. T. W. Chu, D. H. Olson, E. W. Sheppard, S. B. McCullen and others, J. Am. Chem. Soc., 1992, 114, 1083410843.

12 D. Zhao, Q. Huo, J. Feng, B. F. Chmelka and G. D. Stucky, J. Am. Chem. Soc., 1998, 120, 6024-6036.

13 A. Mehdi, C. Reye and R. Corriu, Chem Soc Rev, 2011, 40, 563574.

14 S. Jebors, S. Cecillon, C. Faye, C. Enjalbal, M. Amblard, A. Mehdi, G. Subra and J. Martinez, J. Mater. Chem. B, 2013, 1, 65106515.

15 S. Jebors, C. Enjalbal, M. Amblard, A. Mehdi, G. Subra and J. Martinez, J. Mater. Chem. B, 2013, 1, 2921-2925.

16 A. Mehdi, J. Mater. Chem., 2010, 20, 9281.

17 J. J. E. Moreau, L. Vellutini, M. Wong Chi Man, C. Bied, P. Dieudonné, J.-L. Bantignies and J.-L. Sauvajol, Chem. - Eur. J., 2005, 11, 1527-1537.

18 J. J. E. Moreau, L. Vellutini, M. Wong Chi Man and C. Bied, J. Am. Chem. Soc., 2001, 123, 1509-1510.

19 M. P. Conte, N. Singh, I. R. Sasselli, B. Escuder and R. V. Ulijn, Chem Commun, 2016, 52, 13889-13892.

20 M. Reches and E. Gazit, Science, 2003, 300, 625-627.

21 M. Reches and E. Gazit, Nano Lett., 2004, 4, 581-585.

22 M. Zelzer and R. V. Ulijn, Chem. Soc. Rev., 2010, 39, 3351-3357.

23 J. Ryu and C. B. Park, Angew. Chem. Int. Ed., 2009, 48, 48204823.

24 C. H. Görbitz, Chem. Commun., 2006, 2332-2334. 
25 D.-H. Kim and N.-J. Hong, Bull. Korean Chem. Soc., 2012, 33, 261-269.

26 D. Piovesan, G. Minervini and S. C. E. Tosatto, Nucleic Acids Res., 2016, 44, W367-W374.

27 J. Alauzun, A. Mehdi, C. Reyé and R. J. P. Corriu, J. Am. Chem. Soc., 2005, 127, 11204-11205.

28 J. Alauzun, A. Mehdi, C. Reyé and R. J. P. Corriu, Chem Commun, 2006, 347-349.

29 J. Alauzun, A. Mehdi, C. Reyé and R. J. P. Corriu, J Mater Chem, 2005, 15, 841-843.

30 E. Besson, A. Mehdi, C. Reyé, P. Gaveau and R. J. P. Corriu, Dalton Trans., 2010, 39, 7534.

31 R. Mouawia, A. Mehdi, C. Reyé and R. J. P. Corriu, J. Mater. Chem., 2008, 18, 2028. 